\title{
Research on IFLP optimization model for carbon emission reduction
}

\author{
Qiannan GUO* \\ Northeast Forestry University, China
}

\begin{abstract}
This study proposed an optimization model combined with Binding Interval Linear Programming (ILP) and Fuzzy linear programming (FLP) Methods and further analyzed from the views of economic output, energy consumption, carbon dioxide emission and emission cost. The optimization model results demonstrated that the heavy energy consumption industries will significantly reduce, and the target of the carbon dioxide emissions per unit of GDP reduction decrease by $40 \%-45 \%$ from 2005 to 2020 . In addition, the economic development model will trend to optimize the allocation of resources and green economy. However, a single low-carbon economic policy will always have shortcomings and low efficiency in emission reduction. Hence, the government should combine all emission reduction policies together and establish a lowcarbon economy system that practice production activities need.
\end{abstract}

\section{Research background}

China puts a positive spin on reducing $\mathrm{CO}_{2}$ emissions by introducing reduction, capture and storage technologies and issuing related policies on these technical means [1]. However, the domestic resource structure and production mode are hindering $\mathrm{CO}_{2}$ emissions reduction, causing contradiction between rapid economic growth and environmental protection [2].

To balance the economy-environment-energy relationship, the system feedback is simulated as an adjustable mechanism in the model or external adjustment [3-5], and the interval linear programming (ILP) is used to handle the uncertain information. To address the subjective uncertainty, the fuzzy linear programming (FLP) is introduced for economic restructuring and energy planning as the probability distribution or membership extent of variables (or parameters) are hard to obtain in the real world [6-9]. ILP and FLP were coupled to cope with a considerable amount of uncertain information among economy, energy and environment, leading to more stable decision-making results of the optimization model $[10,11]$.

\section{Determination of objective function and constraints}

Aiming to minimize the cost of $\mathrm{CO}_{2}$ emission reduction in the target year, the target total $\mathrm{CO}_{2}$ emissions, energy consumption, domestic economic growth and industrial economic

*Corresponding author: 574943180@qq.com 
growth are selected as constraints in this study[12]. The satisfaction should be precisely limited by IFLP method with certain confidence level.

\subsection{Setting of objective function}

$$
\operatorname{Min} f=\sum_{i=1}^{I} \sum_{j=1}^{J} \alpha \cdot X G O_{i}^{ \pm} \cdot U E C_{i j}^{ \pm} \cdot E \widetilde{C}_{i j}^{ \pm} \cdot \theta_{j}^{ \pm}
$$

In the formula, $f$ is total cost of $\mathrm{CO}_{2}$ emission reduction in 2020 (in one hundred million Yuan); $i$ is industry, with 27 in total; $j$ is fossil energy, with $j=1$ as coal, $j=2$ as natural gas, $j=3$ as oil and $j=4$ as electricity; $\mathrm{XGO}_{i}$ is target output value of each industry in 2020 (in one hundred million Yuan), which is the decision-making variable; $\mathrm{UEC}_{i j}$ is consumption of energy $j$ per unit output value of industry $i$ (in one million tons of standard coal); $\alpha-1$ is $\mathrm{CO}_{2}$ emissions per one million tons of standard coal (in one million tons of $\mathrm{CO}_{2} /$ one million tons of standard coal), with the value of 2.4567 tons of $\mathrm{CO}_{2}$ per one ton of standard coal recommended by Energy Research Institute, National Development and Reform Commission; $\mathrm{EC}_{i j}$ is cost of $\mathrm{CO}_{2}$ emissions reduction for energy $j$ in industry $i$ (in one hundred million Yuan/one million tons); $\theta_{j}$ is ratio of target $\mathrm{CO}_{2}$ emission reduction of industry in 2020 .

\subsection{Determination of constraints}

- Constraint on target total $\mathrm{CO} 2$ emissions:

China unveiled at the Copenhagen conference its target to reduce greenhouse gases emitted per unit GDP by $40-45 \%$ from that in the benchmark year, reaching the 2020 control requirement on total $\mathrm{CO} 2$ emissions after industrial restructuring.

$$
\sum_{i=1}^{I} \sum_{j=1}^{J} \alpha^{ \pm} \cdot U E C_{i j}^{ \pm} \cdot X G O_{i}^{ \pm} \cdot 10^{-4} \leq\left(1-\beta^{ \pm}\right) \cdot B C I^{ \pm} \cdot T G D P^{ \pm}
$$

In the formula, $\beta$ is target $\mathrm{CO}_{2}$ emissions reduced per unit GDP in 2020 , which is $40 \%$ $45 \%$; $B C I$ is $\mathrm{CO}_{2}$ emission intensity per unit GDP (in one million tons of $\mathrm{CO}_{2} /$ one hundred million Yuan per unit GDP) in 2005; TGDP is target GDP in 2020 (in one hundred million Yuan).

- Constraint on target total energy consumption:

According to the Notice of Strategic Action Plan for Energy Development (2014-2020) released by the General Office of the State Council ,the primary energy consumption will be capped at 4.8 billion tons of standard coal by 2020 , of which the fossil energy should be less than $85 \%$, about 4.08 billion tons.

$$
\sum_{i=1}^{I} \sum_{j=1}^{J} U E C_{i j}^{ \pm} \cdot X G O_{i}^{ \pm} \cdot 10^{-4} \leq T E C^{ \pm}
$$

In the formula, TEC is target total fossil energy consumption in 2020 (in one million tons of standard coal).

- Constraint on domestic economic growth:

The sum of output values of all industries is expected to meet the economic growth demand in China. According to the planning requirements for overall economic development in the future, this constraint is to avoid the decline in economic growth through model optimization. 


$$
\sum_{i=1}^{I} X G O_{i}^{ \pm} \geq\left(1+\delta^{ \pm}\right)^{5} \cdot I G D P
$$

In the formula, $\delta$ is target domestic annual economic growth (\%); IGDP is domestic GDP in 2015 (in one hundred million Yuan).

- Constraint on gross industrial economic growth:

The constraint on gross industrial economic growth is that industries should appropriately adjust its economic growth within a certain range.

$$
X G O_{i}^{ \pm} \geq L G O_{i}^{ \pm} \text {and } X G O_{i}^{ \pm} \leq U G O_{i}^{ \pm}, \forall i
$$

In the formula, LGO is lowest gross output (in one hundred million Yuan); UGO is uppermost gross output (in one hundred million Yuan).

- Constraint on economic growth of each industry:

Constraints on energy consumption in various industries means that optimizing the composition of energy consumption needs to meet the energy needs of the industry without affecting economic development.

$$
X G O_{i}^{ \pm} \geq D I E_{i}^{ \pm} \text {and } X G O_{i}^{ \pm} \leq U I E_{i}^{ \pm}, \forall i
$$

In the formula, DIE is the lowest industry output (in one hundred million Yuan); UIE is uppermost industry output (in one hundred million Yuan).

- Non-negative constraint:

$$
X G O \underset{i}{ \pm} \geq 0, \forall i
$$

\section{Analysis of model calculations}

\subsection{Analysis of economic output structure}

As shown in Figure 1, 27 industries are classified into energy intensive dependence, equipment manufacturing and other textile ones respectively. Optimization model results reveal that the target year (2020) will see economic consumption ratio of energy intensive dependence industries significantly decreasing $[12.59,14.61] \%$, and of equipment manufacturing and other textile industries rising $[5.6,7.25] \%$ and $[5.31,9.01] \%$, respectively, from the 2010 levels. Therefore, the IFLP optimization model can reasonably adjust the economic structure and provide more stable decision-making and guidance for improving the modern energy market system and deepening the key emission reduction industries.

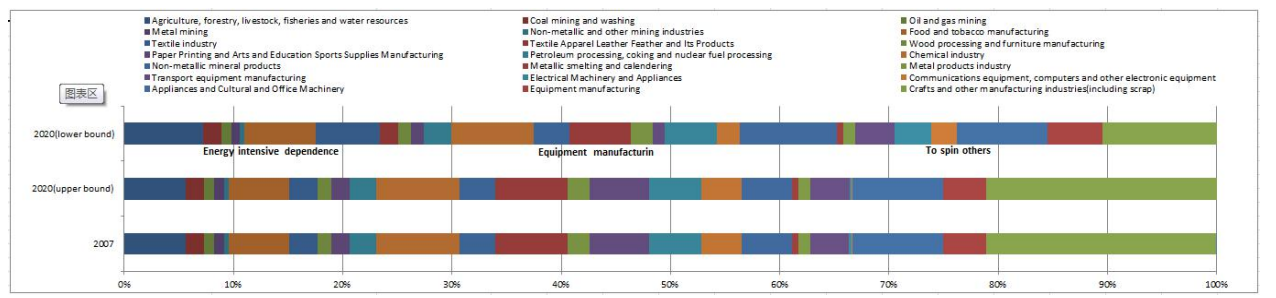

Fig. 1. Uncertainty ratio analysis of economic output in main industries in 2010 and the target year (2020)

\subsection{Analysis of energy consumption structure}


China's energy consumption ranking is coal $>$ oil $>$ electricity $>$ natural gas. According to the optimization model, the total energy consumption in 2020 is [47.57, 47.78] million tons, and the optimization results meet the national planning requirements within a moderate range. As shown in Figure 2, model optimization indicates that energy consumption ranking will be constant in 2020. However, as top three total energy-consuming industries ,oil processing, coking and nuclear fuel processing industry, metal smelting and rolling processing industry, and electricity and heat production and supply industry accounted for $68.82 \%$ coal consumption in 2010.Their energy consumption decreased [29.38, 32.45] \%. Meanwhile, after adjusting the deterministic model using IFLP optimization model, the energy consumption of four industries including transportation equipment manufacturing; communications equipment; computers and other electronic equipment; transportation, storage and post, will rise significantly $[14.33,15.81] \%$ from the 2010 level until 2020.

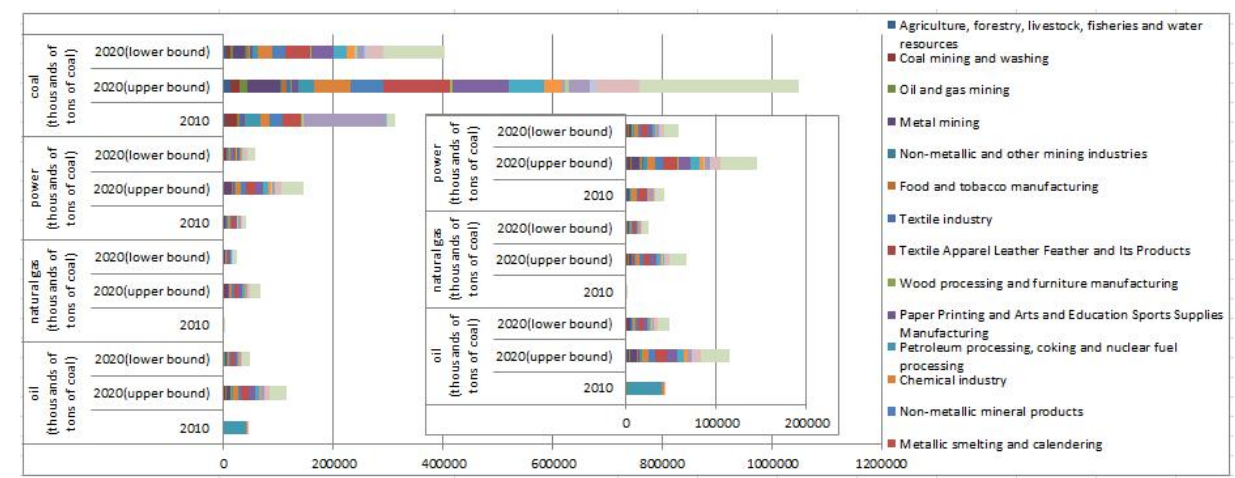

Fig. 2. Uncertainty ratio analysis of energy consumption in 2010 and the target year (2020)

Economic restructuring puts a positive spin on energy restructuring and blindly pursuing carbon emission reduction in the energy structure will lead to economic disorder. Thus, adjusting of economic output structure and energy consumption structure should be limited within a certain range. In this paper, the IFLP optimization model for carbon emission reduction has offered a more stable decision basis for the relationship among economic structure, energy consumption and carbon emission reduction, making results more reliable.

\subsection{Analysis of $\mathrm{CO}_{2}$ emissions}

Considering data of 2010 as an example, China's $\mathrm{CO}_{2}$ emissions level is consistent with its energy consumption ranking. About $90 \%$ of emission came from burning fossil fuels, which indicate a strong positive correlation between them. This positive correlation is related to China's current energy structure dominated by fossil energy. China's policy for $\mathrm{CO}_{2}$ emission reduction aims to promote clean and efficient exploitation and utilization of coal. China will emit [341, 372] billion tons of $\mathrm{CO}_{2}$ in 2020 resulted by optimization model (shown in Figure 3). This target can be achieved adequately if the guidance of this model is strictly implemented.

Relevant policies point out that promotion of the natural gas industry and alternative energy should be made continuously. In the IFLP optimization model for carbon emission reduction, it can be projected that by 2020 , the energy use ratios of natural gas and electricity will rise by $[1.85,2.03] \%$ and $[2.40,2.68] \%$, respectively, from 2010 to 2020 . According to the Reply of the State Council on China's National Plan for Climate Change (2014-2020) (G.H. [2014] No. 126) by 2020, the $\mathrm{CO}_{2}$ emissions per unit GDP in 2020 will fall almost $40-45 \%$ compared with 2005 : the ratios of using non-fossil fuel resources in 
primary energy, forest area and storage volume can reach the standards expected in the optimized deterministic model. This model is devoted to transforming energy intensive dependence industries which contribute higher emissions to equipment manufacturing industries and other textile industries.

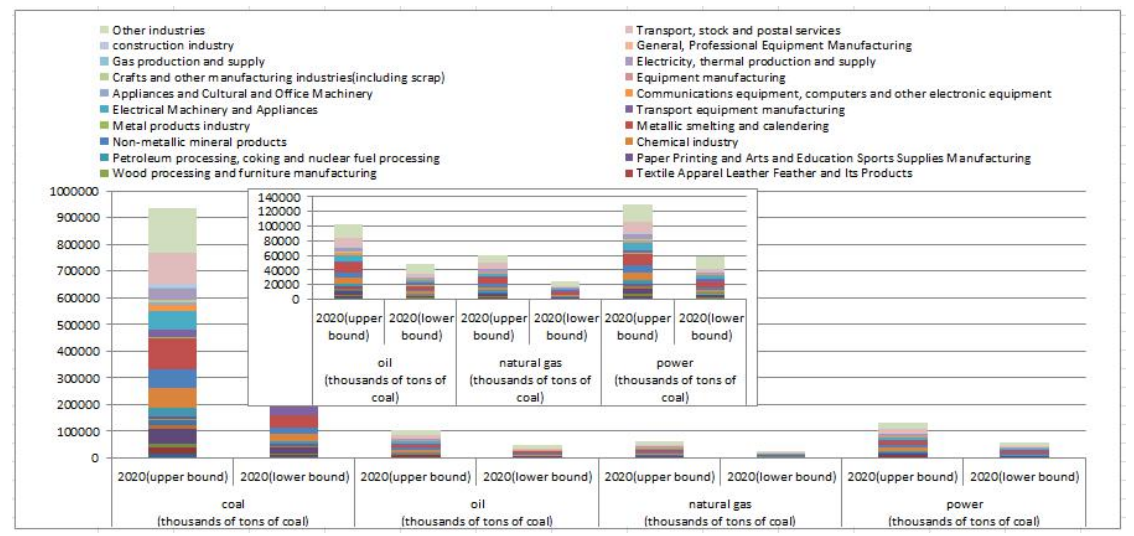

Fig. 3. Uncertainty analysis of $\mathrm{CO}_{2}$ emissions in the target year (2020)

\subsection{Analysis of cost for $\mathrm{CO}_{2}$ emission reduction}

Reducing the cost of carbon dioxide emission reduction can better inhibit the non-benign development of the company. Therefore, it is necessary to increase the technological investment in petrochemical and other high-energy-consuming industries, accelerate the transformation and upgrading of technology equipment, reduce energy consumption, improve the utilization efficiency, and reduce the carbon dioxide emissions. It has made significant contributions to the environmental protection and control of the malignant development of high-emission companies. As shown in Figure 4, according to the IFLP optimization model results, the chemical industry, non-metallic mineral product industry, metal smelting and rolling processing industry, construction industry, and transportation, storage and post industry are high-cost industries for carbon emission reduction, accounting for $[57.20,58.00] \%$. Thus, they are all industries with potential for emission reduction.

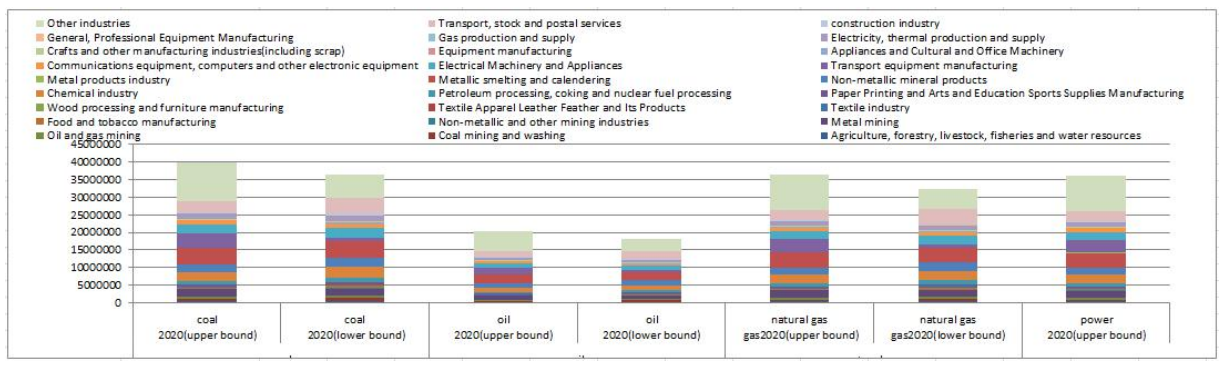

Fig. 4. Cost uncertainty measurement analysis of $\mathrm{CO}_{2}$ emissions in the target year (2020)

\section{Conclusion}

In this paper, based on low-carbon economic development and IFLP theory, the following main options can be concluded:

- In the target year (2020), the energy consumption in intensive dependence industries should have a significant adjustment, from extensive economic growth to relying on the optimal allocation of resources and clean energy. The optimization model enables 
the market economy to play a guiding role in allocating resources. Precisely, adjusting to improve the equipment manufacturing and other textile industries fully verifies the optimization of resources.

- China's energy consumption ranking in 2010 was coal $>$ oil $>$ electricity $>$ natural gas, which will be unchanged in 2020 after optimization. In the national energy strategy for development, it is emphatically pointed out that in order to promote the basic principles of clean and efficient development and utilization of coal, domestic production of petroleum should be steadily increased, and natural gas should be vigorously developed to replace energy.

- China's energy consumption ranking in 2020 is expected to be fixed, although the consumption of natural gas and electricity will rise. The optimization model is devoted to transforming energy intensive chemical industries which contribute higher emissions to equipment manufacturing industries and other textile industries.

- The cost measurement analysis of $\mathrm{CO}_{2}$ emission reduction is the scientific basis for formulating and implementing carbon emission reduction policy. Nowadays, China relies heavily on fossil energy sector and the forced emission reduction will bring a serious impact on macro economy, i.e. $\mathrm{CO}_{2}$ emission reduction has a high macroeconomic price or cost.

\section{References}

1. Zou Wei, Hu Li, Lin Shumin, et al. Intrinsic driving force of rural land integrated consolidation [J]. Chinese Society of Agricultural Engineering, 2013, 29(8): 224-231.

2. Li Yu'e, Ma Xin and He Xiaojia. The Progress on adaptation negotiations since adoption of bali action plan and future needs analysis [J]. Advances in Climate Change Research, 2014, 10(2): 135-141.

3. The State Council. Circular of the State Council concerning issuance of the 12th fiveyear plan for energy conservation and emission reduction (G.F. [2012] No. 40) [J]. http.//www. gov. cn/zwgk2012-08/21/content_2207867. htm, 2012.

4. Cai Bofeng. Research on greenhouse gas emissions inventory in the cities of china [j]. china population, Resources and Environment, 2012, 22(1): 21-27.

5. Lin Boqiang and Liu Xiying. Carbon emissions at the urbanization stage: influencing factors and emission reduction strategies [J]. Economic Research Journal, 2010, 8(1): 22.

6. Du Tingting, Mao Feng and Luo Rui. Study on China's economic growth and co2 emissions [j]. china population, resources and environment, 2007, 17(2): 94-99.

7. Birge J R, Louveaux F. Introduction to stochastic programming[M]. Springer Science \& Business Media, 2011.

8. Zeng Guangming and Huang Guohe. Uncertainty theory and methods in environmental science and engineering [M]. Changsha: Hunan University Press, 2002.

9. Chakraborty.D, Redefining chance-constrained programming in fuzzy environment, Fuzzy Sets and Systems 2002, (125), 327-333.

10. Yang N, Wen F. A chance constrained programming approach to transmission system expansion planning[J]. Electric Power Systems Research, 2005, 75(2): 171-177.

11. Nam K M, Selin N E, Reilly J M, et al. Measuring welfare loss caused by air pollution in Europe: A CGE analysis[J]. Energy Policy, 2010, 38(9): 5059-5071.

12. Li Zengfu and Zheng Youhuan. Research in the implementation mechanism of the "low -carbon city" [J]. Economic Geography, 2010 (6): 949-954. 